\title{
Experiments of Transient Condensation Heat Transfer on the Heat Flux Senor
}

\author{
Xuwen Wang ${ }^{1}$ Q Qiusheng Liu ${ }^{1}$. Zhiqiang Zhu ${ }^{1} \cdot$ Xue Chen $^{1}$
}

Received: 23 November 2014 / Accepted: 7 April 2015 / Published online: 24 April 2015

(C) Springer Science+Business Media Dordrecht 2015

\begin{abstract}
The influence of transient heat transfer in different condensation condition was investigated experimentally in the present paper. Getting condensation heat and mass transfer regularity and characteristics in space can provide theoretical basis for thermodynamic device such as heat pipes, loop heat pipes and capillary pumped loops as well as other fluid management engineering designing. In order to study the condensation process in space, an experimental study has been carried out on the ground for space experiment. The results show that transit heat transfer coefficient of film condensation is related to the condensation film width, the flow condition near the two phase interface and the pressure of the vapor and non-condensable gas in chamber. On the ground, the condensation heat flux on vertical surface is higher than it on horizontal surface. The transit heat flux of film condensation is affected by the temperature of superheated vapor, the temperature of condensation surface and non-condensable gas pressure. Condensation heat flux with vapor forced convection is many times more than it with natural convection. All of heat flux for both vapor forced convection and natural convection condensation in limited chamber declines dramatically over time. The present experiment is preliminary work for our future space
\end{abstract}

Qiusheng Liu

liu@imech.ac.cn

Xuwen Wang

wangxuwen@imech.ac.cn

1 Key Laboratory of Microgravity, Institute of Mechanics, Chinese Academy of Sciences, Beijing 100190, China experiments of the condensation and heat transfer process onboard the Chinese Spacecraft "TZ-1" to be launched in 2016.

Keywords Two-phase flow · Condensation .

Microgravity $\cdot$ Transient heat flux

\author{
Nomenclature \\ $T$ Temperature \\ $x$ Coordinate \\ a Thermal diffusivity \\ $\tau \quad$ Time \\ $s \quad$ Vapor-liquid interface Coordinate \\ $\rho \quad$ Liquid density \\ $H$ Latent heat \\ $\lambda \quad$ Liquid conduct coefficient \\ $c \quad$ Liquid heat capacity
}

\section{Introduction}

Both evaporation and condensation are important phenomena in the industrial engineering, such as power plant's water cycle system, refrigerant cycle in air condition and other heat exchanger equipment. Condensation in microgravity is one of the most important phenomena in space emission vehicles in the future. Condensation in space such as environment control, human life support in satellites and other manned spacecraft is widely used. However, the condensation heat and mass transfer occurrence at the liquid-vapor interface and in the gas phase are not well understood, which is affected by several reasons. Without gravity interference, condensation in space can easily reveal the physics laws. For understanding special behaviors of the condensation heat and 
mass transfer in microgravity environment, an experimental study of transient condensation has been carried out on the ground. The present study constitutes the ground phase evaporator and condensation experiment in TZ-1, which is planned to be launched in 2016. The initiative of the space experiment is aimed at amassing comprehensive evaporation and condensation in microgravity. The experimental study on the ground was conducted by FC-72 and alcohol liquid. This paper presents the transient heat flux on a heat flux sensor in different operating condition such as condensation with natural convection or forced convection, the different pressure of noncondensable gas, different angle of condensation surface and horizontal plane, and different condensation surface temperature. The present study also contains the visualization study of film and dropwise condensation. Finally, a summary of the source of transient condensation is presented.

Due to different vapor and cooling surface properties, condensation on the surface can be classified into dropwise condensation and filmwise condensation. As shown in Fig. 1, the condensable molecular driven by density difference and pressure approach to the two phase interface. After releasing the latent heat, the molecular changes from gas phase into liquid phase. Because of the different liquid surface tension and solid property, the liquid will display film and dropwise shape. It is said that heat transfer coefficient for dropwise condensation is approximately 15-20 times higher than that for filmwise condensation in the same vapor condition. This is because dropwise condensation can be divided into three different periods: dropwise coming into being on the beginning; substantial growth of drops by condensation; growth of drops by condensation accompanied with the coalescence and falling off. Noriyuki Watanabe (2014) conducted a lot of experimental investigation on dropwise condensation of steam and derived empirical dropwise distribution densities. They have found that the time-averaged drop size distribution densities in the range of drops diameter $r \leq 0.4 \mathrm{~mm}$ were in excellent agreement with theoretical correlations by Rose $(2002,1981,1976,1967)$. When the diameter was $0.4 \leq \mathrm{r} \leq 0.9$, the distribution densities were in good agreement with the empirical correlation by Tamasawa (1991) and Collier (1981). Maofei (2011) simulated the process of nucleation, growth, re-nucleation and sweeping of droplet. The results showed that the growth rate of droplets was strongly dependent on the number of initial droplets. The statistical fractal characteristic of droplet and drop size distribution was consistent with experimental observations. Ma (2010) used high speed camera to investigate the evolution of droplet size distribution in dropwise condensation process. For the transient characteristics of droplet size distribution, the primary droplet satisfied

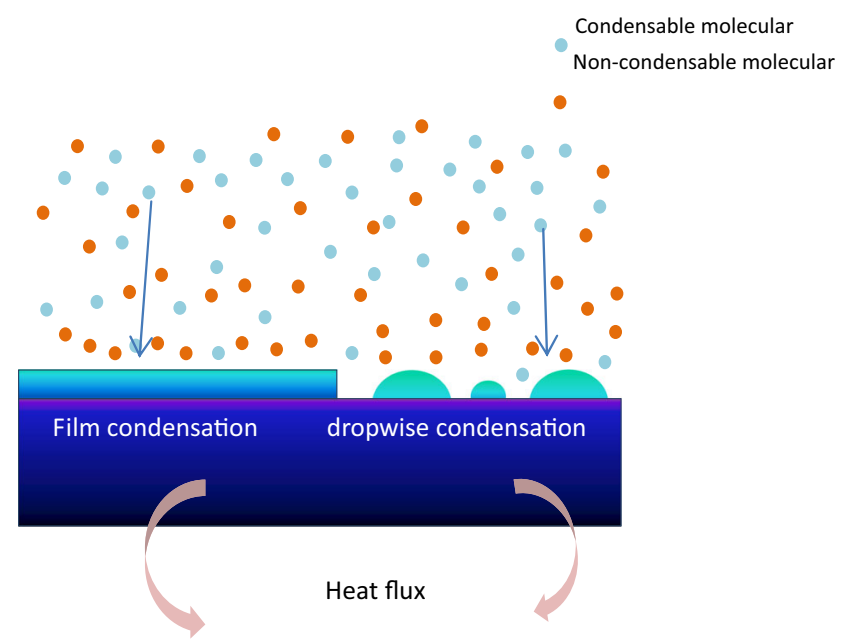

Fig. 1 Schematic of condensation

lognormal distribution and then classical exponential size distribution for steady state. Ma (2000); Baojin (2011); Son (2012); Gebauer (2013); Park (2013) concluded that using organic material on a cooling surface, synthetic material for organic and metal and low surface energy material surface to improve dropwise condensation.

But the majority condensation in engineering practice is film condensation because the dropwise condensation cannot keep long. Hao (2013) used numerical method to simulate the film condensation in noncircular section micro channel. Kondou (2012) conducted the experiments to find vapor heat transfer coefficient for condensation with super-heated $\mathrm{CO}_{2}$ and $\mathrm{R} 410 \mathrm{~A}$ together. They found when the wall temperature reached at saturation point, the heat transfer coefficient gradually deviated from the correlation for single phase cooling. The heat transfer coefficient of $\mathrm{CO} 2$ is approximately $20-70 \%$ higher than that of $\mathrm{R} 410 \mathrm{~A}$ at the same reduced pressures. Kim and Mudawar (2012) presented a theoretical model for annular flow condensation for rectangular micro channels by using control volume based model. Zhao (2014) used numerical method to investigate the ambient air condensation on a cryogenic horizontal tube. The result showed that the superheating has a more significant contribution to increase heat transfer coefficient for air comparing to other vapors. The sub-cooling temperature had a negative effect on the increase of heat transfer coefficient. And they found the buoyancy played a non-negligible role on the flow and heat transfer characteristics for superheated air condensation. Le (2014) derived an analytical solution for steady laminar film condensation with quiescent pure vapors on vertical convex and concave curved walls. Pati (2014); Son (2012); G.H. Tang (2012) used experimental method to investigate condensation heat transfer characteristics for $\mathrm{CO}_{2}$ at high saturation temperatures in a 
horizontal tube. They found the condensation heat transfer coefficients for the smooth- and micro fin-tube increased with the decreasing saturation temperature and increasing mass flux. Lee (2013) conducted an experimental investigate to find the annular condensation of FC-72 in $\}$ in parabolic flight. They found that the different gravity played a pronounced role on thickening the film along the tube. But the mass velocities can decrease the influence of different gravity.

In order to obtain the heat and mass transfer laws of condensation in different stages, a transient condensation experiment has been carried out on the ground. Both filmwise condensation and dropwise condensation are affected by many factors. Therefore, the present study has focused on the effects of some factors such as condensation film width, vapor flow condition, pressure of the vapor and noncondensable gas and properties of the condensation surface. On the ground, the condensation is seriously affected by vapor natural convection and forced convection. A closed chamber without vapor forced convection is fabricated. Owing to conduction for heat transfer and diffusion for mass transfer without convection, condensation generates slowly in microgravity space. We can obtain the deeply understanding of heat and mass transfer in comparison of the experimental results obtained on the ground with those obtained in space. Filmwise condensation is emerged on a flat brass surface which can be treated to get dropwise condensation. The present study on the condensation process is one part of the experimental investigations of evaporation and condensation in microgravity environment onboard the Chinese Spacecraft TZ-1, which is planned to be launched in the end of 2016.

\section{Experimental Investigation}

\section{Apparatus and Procedure}

The experimental apparatus for condensation is shown in Fig. 2. This experimental apparatus are composed of an enclosed test chamber, a vacuum condition controlled system, an observation system, a steam generating system and a temperature controlled system. The steam generating system can provide certain temperature and pressure steam. The temperature controlled system can keep the condensation surface at necessary temperature. The temperature control range is $-5^{\circ}-40^{\circ}$ and temperature resolution is $0.5^{\circ}$. The enclosed chamber is cuboids with the internal cavity of $180 \mathrm{~mm}$ in length, $100 \mathrm{~mm}$ in width and $75 \mathrm{~mm}$ in height, and a condensation parts is installed inside. The optical observation windows are in the front of test chamber, where there is silica glass made of high-grade. On the top of the test chamber, there are two plates of infra glass

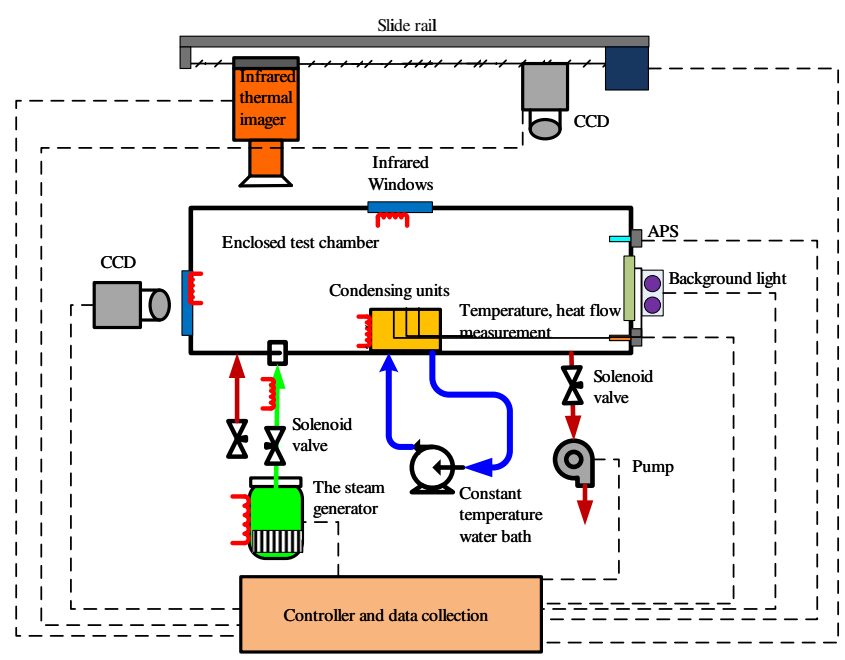

Fig. 2 Schematic of flow loop

for the observation of the condensation test parts by using infra camera. So the condensation surface can be observed from front and top directions by CCD camera and infra camera.

The detailed conception of the condensation part drawing is shown in Fig. 3. The heat flux sensor (outer diameter $20 \mathrm{~mm}, 0.5 \mathrm{~mm}$ width) is installed between copper cylinder and copper cap. The cap of the condensation surface is blacked for infra camera. Coolant water flows in and out from the copper cylinder. Four thermocouples are placed in the cylinder to measure copper cylinder during condensation. The heat transfer flux sensor and temperature by thermocouple scans are made every $0.5 \mathrm{~s}$. The heat transfer flux can be obtained by two methods. One is measured directly by heat transfer flux senor. The other is calculated by the four thermocouples. Heat flux estimates via these methods are in fair agreement (within-25\%). Data runs at each level of sub-cooling surface and other conditions are repeated four times to capture natural data variance. The temperature on the condensation surface is calculated by thermocouples and it is adjusted by infra camera. The temperature and pressure measured in chamber are used to calculate the pressure of non-condensable gas. The steam pressure can be controlled by a vacuum condition system and steam generating system. Pure alcohol and FC-72 are heated by heaters in the steam generating system, which is controlled by PID controller, so that the steam injected is at accuracy temperature for different experimental conditions. The temperature control range is $40^{\circ}-100^{\circ}$ and temperature resolution is $0.5^{\circ}$. The velocity of steam injected is $0-0.05 \mathrm{~g} / \mathrm{s}$. On the initiative stage of experiment, the vacuum pump is used, and then turn on the valve, the steam can be injected into the chamber. 

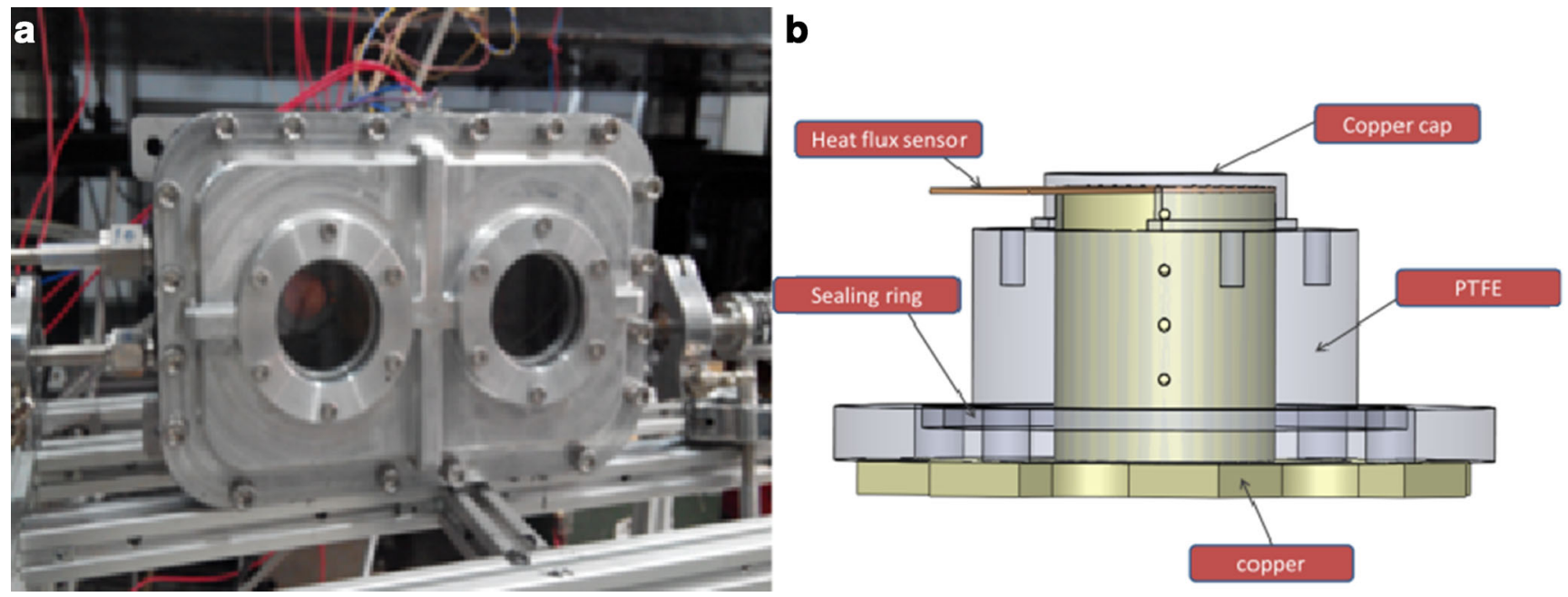

Fig. 3 (a) Enclosed test chamber; (b) Condensation test part

\section{Photographic Methods}

Two different cameras are used to capture images of the vapor condensation on the heat flux sensor. The images of the film condensation are captured by a CCD camera at 10 fps with 1280*1024-pixel resolution from the top view. The temperature profile of condensation surface is caught by an infra camera with $640 * 480$-pixel resolution, of which the temperature resolution is $0.05^{\circ}$.

\section{Experimental Results}

Figure 4 shows film and dropwise condensation images in a special condition. When the cooling system don't work, the condensation surface is clear. At one time turn on the cooling water valve, the cooling water suddenly flow into the condensation part. Heat flux reach at a maximum in a short time, and at the same time, condensation occur. Along with the time, the liquid film widths thicken gradually and droplets of dropwise condensation enlarge gradually. After heat flux reaches at the maximum, the value is decreasing gradually. For different operating condition, the trend is similar. It can be explained by one dimension pure vapor condensation without liquid, vapor flow and without gravity. Heat transfer over the time is

$q=-\lambda \frac{\partial T}{\partial x}=\rho H \frac{d s}{d \tau}=\rho H \beta a^{-\frac{1}{2}} \tau^{-\frac{1}{2}}$

Equation displays that the heat transfer decreases with time and the relation is $-1 / 2$ power. It is showed the trend of the heat transfer flux, but at the start time, the heat transfer flux is infinity, which is inconsistent with the reality.

Equation 1 is reached as follows:

$\frac{\partial^{2} T}{\partial x^{2}}=\frac{1}{a} \frac{\partial T}{\partial \tau}$
Fig. 4 Different stages of film condensation and dropwise condensation

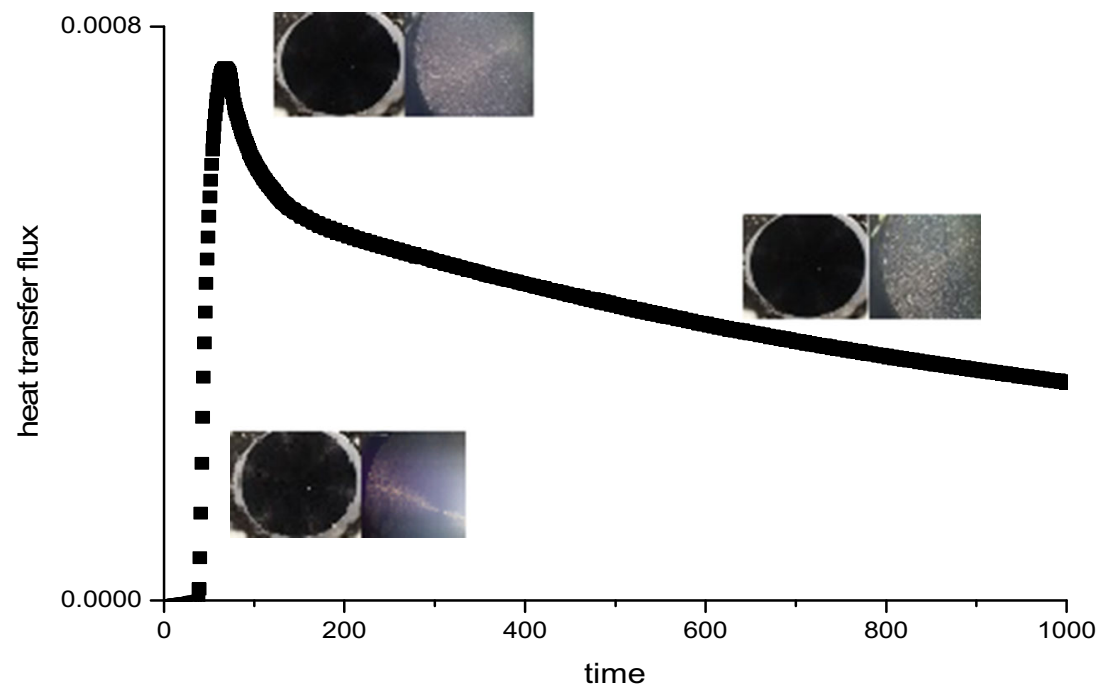


Fig. 5 Variations of experimentally-determined condensation heat transfer with time for forced convection and without it, alcohol, vertical, pure vapor, $5^{\circ}$ condensation surface

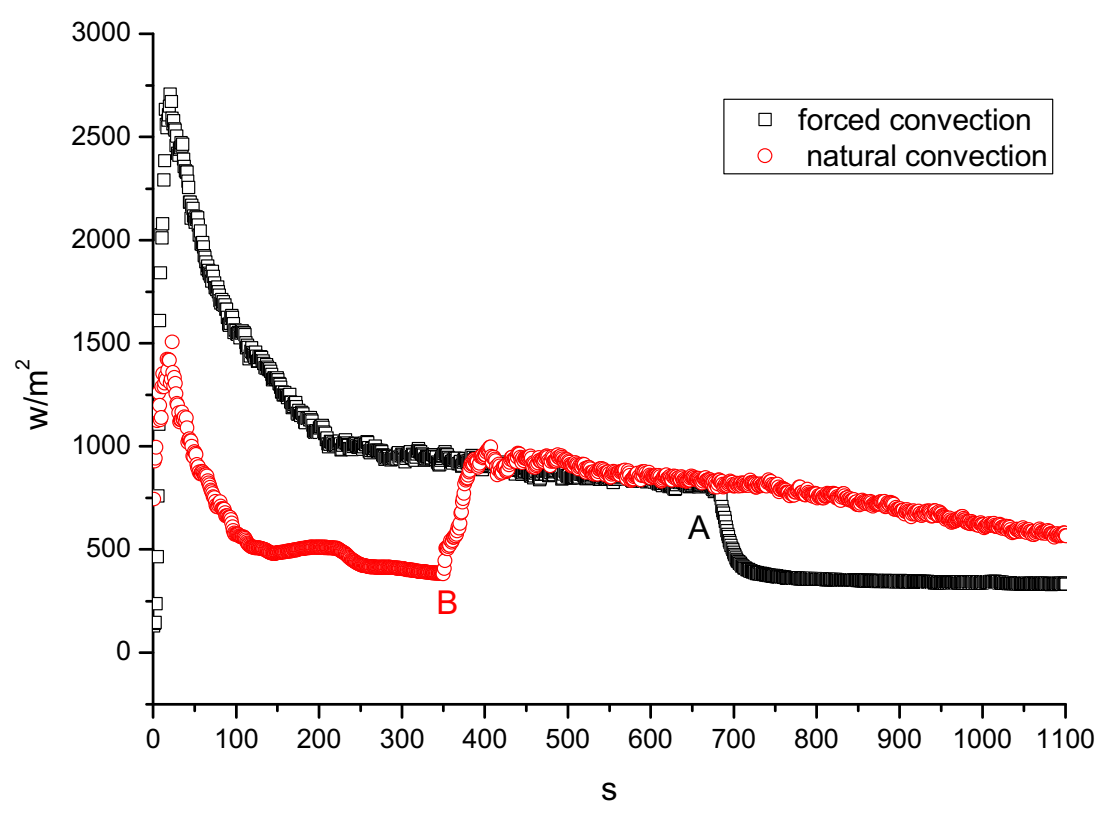

Boundary condition:

$T(0, \tau)=T_{0, T}(s, \tau)=T_{m},-\lambda \frac{\partial T}{\partial x}=\rho H \frac{d s}{d \tau}$

The liquid temperature is assumed to meet quadratic polynomial relationship. a1, b1, c1 is constants.

$T(x, \tau)=a 1+b 1(x-s)+c 1(x-s)^{2}$

The present heat transfer coefficients to those of experimental data are compared with forced convection and natural convection flow (see in Fig. 5). At point $A$ the force convection was stopped, and at point B the forced convection was introduced inside condensation test chamber. For each of condensation condition, heat flux is at the highest at the start time and decreases along the condensation time. This trend is attributed to the condensation film being zero at the start time and increasing in thickness along the condensation time. Furthermore, heat transfer with the natural convection is dominated by the conduction resistance across the film, which increases with time. This trend is same for the three condensation condition. However, the trend of heat transfer for condensation by experiments is lower than the theory. It is can be explained by the pressure of the steam in the closed tanker and the flow condition of the gas phase.

Figure 6 shows the comparison of the present heat transfer coefficients with different non-condensable pressure for natural convection on vertical angle surface. Owing to the increasing of non-condensable gas, the heat transfer coefficient decreases significantly. That is because the increasing of non-condensable gas leads the increasing of contact resistance of steam and the condensation surface. When the steam pressure approaches to a certain value, the condensation heat transfer is stopped. That is similar to the water vapor in the air for the dew temperature.

Figure 8 Variations of experimentally-determined condensation heat transfer with time for different angle of condensation surface and horizontal, alcohol vapor, $10^{\circ}$ condensation surface, $20 \mathrm{kPa}$ non-condensable gas

The comparison results of the present heat transfer coefficients to those of different condensation surface temperature are given in Fig. 7. It reveals that big difference temperature for saturate temperature and condensation surface can lead to higher heat transfer flux. It is also obtained by theory before.

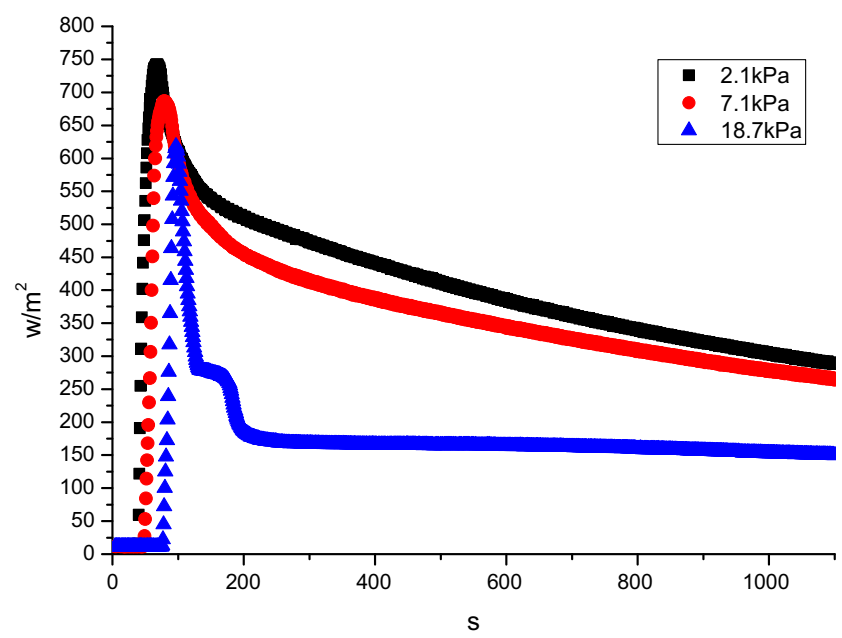

Fig. 6 Variations of experimentally-determined condensation heat transfer with time for different non-condensable gas pressure, alcohol, vertical, $5^{\circ}$ condensation surface 
Fig. 7 Variations of experimentally-determined condensation heat transfer with time for different condensation surface temperature, alcohol vapor, $60^{\circ}, 20 \mathrm{kPa}$ non-condensable gas

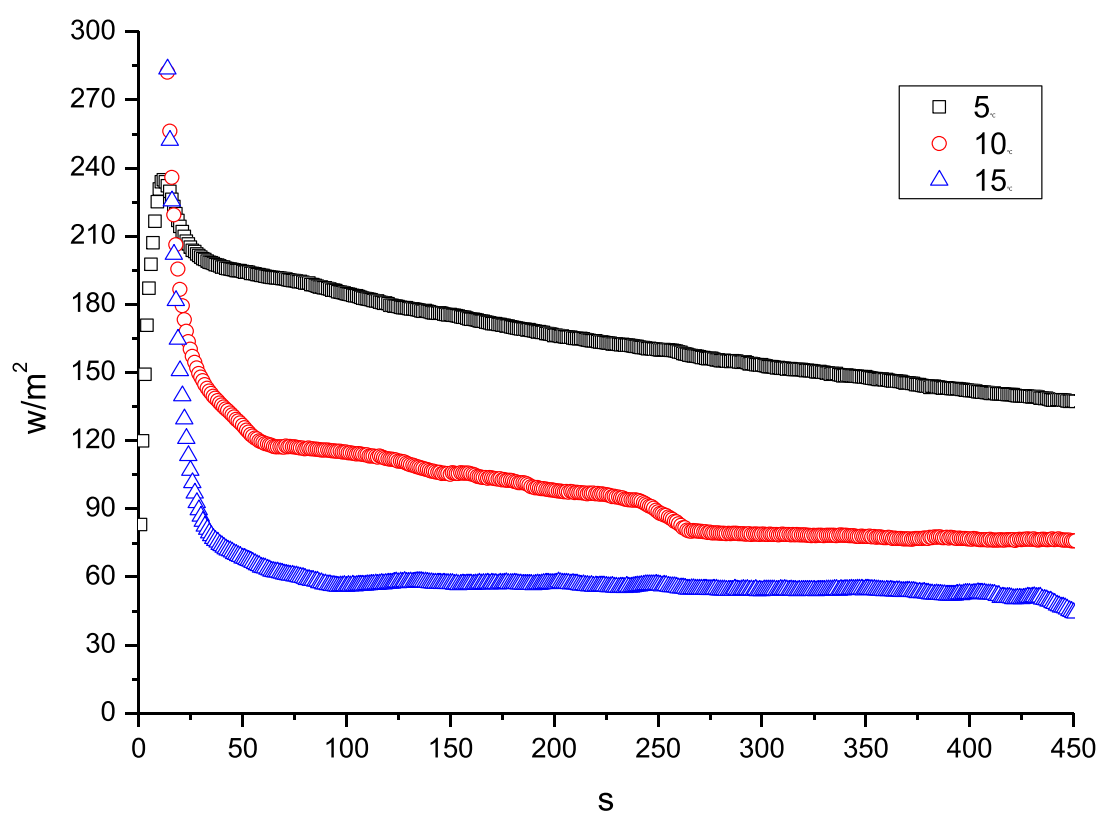

Figure 8 compares the present heat transfer coefficients for those of different installation methods. It is showed that heat transfer on the vertical condensation surface is larger than it on the horizontal and up in down surface. This is because the gravity has pulled the liquid film from the surface and the height of condensation film is thinner than the other conditions. The surface tension can easily pull the film into a dropwise on the up in down surface, so the heat transfer is bigger than it on the horizontal surface. On the ground, every experiment can be affected by gravity and because the factors are in couple, the influence of natural convection in each condition cannot be gotten. In space, the natural convection is vanished.

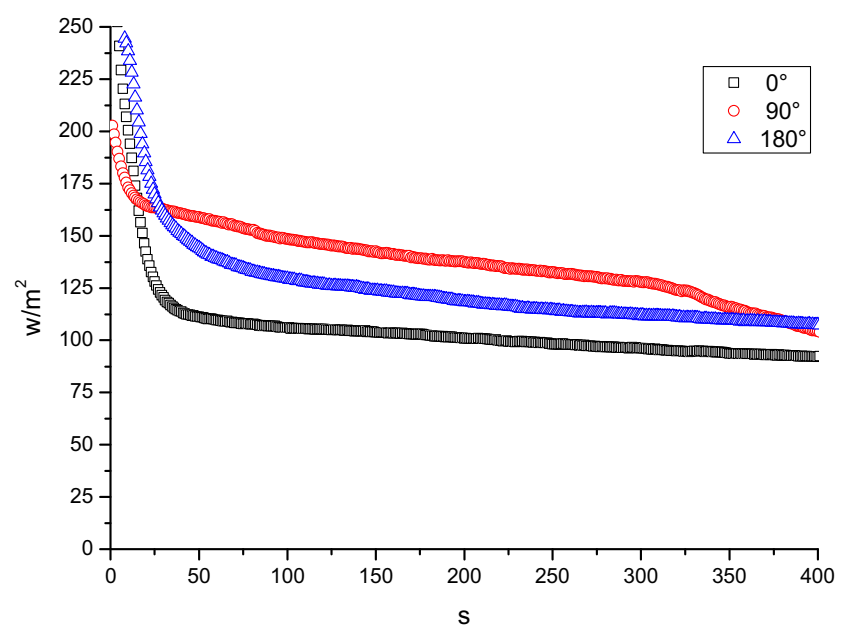

Fig. 8 Variations of experimentally-determined condensation heat transfer with time for different angle of condensation surface and horizontal, alcohol vapor, $10{ }^{\circ} \mathrm{C}$ condensation surface, $20 \mathrm{kPa}$ noncondensable gas
As shown in Fig. 9, the start time heat flux maximum is approximate between $2200 \mathrm{w} / \mathrm{m}^{2}$ and $1000 \mathrm{w} / \mathrm{m}^{2}$. The improved boundary condition should be used to Eq. 2 for realistic value.

Through the analysis above, it can be shown that the resistance for film condensation includes film conduction resistance and mass transfer resistance (Fig. 10). The film conduction resistance is related to condensation film height and the flow inside. Different installation method can lead to the film height changed. Mass transfer resistance contains steam flow condition near condensation surface and pressure of condensation steam. For the steam flow, force convection is helpful for condensation than natural convection on the ground. The pressure of condensation steam can also influence the condensation.

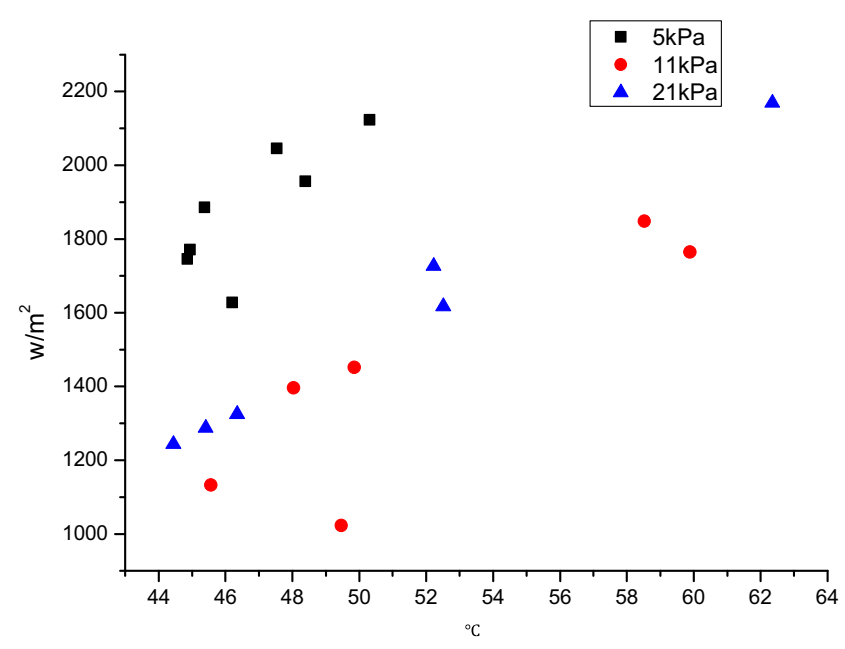

Fig. 9 heat flux at the condensation beginning for different noncondensable gas, $\mathrm{FC}-72$, vertical, $10^{\circ} \mathrm{C}$ condensation surface 


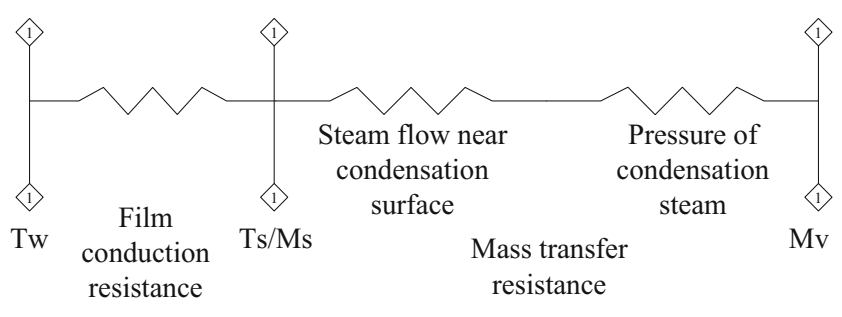

Fig. 10 Resistance for film condensation

\section{Conclusions}

The influence of different condensation conditions on transient condensation heat transfer on the ground was investigated experimentally in the present paper. The experimental results show that the heat flux of film condensation can be affected by the flow of the vapor, and the Heat transfer coefficient with forced convection is many times more than without it. This is because only the vapor molecules reach the nearby of condensation film, the vapor molecules release its latent heat and condensation occur. Increasing the vapor velocity near the condensation film surface can improve condensation. The vapor velocity is a main reason for heat and mass transfer resistance for condensation. The heat transfer of forced convection and natural convection condensation in limited chamber declines sharply over time. Because in the same molecules velocity, in condensation process the liquid film width increase. The heat transfer through the liquid film by conduction became harder and it became the main resistance for condensation. The heat transfer coefficient of dropwise condensation is higher than filmwise condensation in the same condition because the liquid film width for dropwise condensation is thinner. Decreasing the liquid film width is another main reason for improving condensation.

Heat transfer coefficient of the film condensation is affected by the temperature of superheated vapor, the temperature of condensation surface and non-condensable gas significantly. The non-condensable gas pressure can inhabit vapor molecules moving to condensation film surface. For vapor natural convection condensation comparing to forced convection condensation, the non-condensable gas molecules can deteriorate heat transfer of condensation. Heat transfer coefficient without thermal buoyancy convection in space will be lower than it on the ground.

On the ground, heat transfer of vertical surface with gravity is bigger than the horizontal surface. This is because gravity can draw the liquid film from the condensation surface.

Heat transfer at start time is affected by the condensation surface temperature and non-condensable gas. Only surface temperature decline under saturation temperature, could the condensation generate. If the non-condensable gas had a higher proportion, it is hard and slow to generate condensation. That may be the non-condensable gas molecules prohibit the liquid droplet nucleation generation.

Acknowledgments This research was financially supported by the China's Manned Space Program (TZ-1), the Strategic Priority Research Program on Space Science, the Chinese Academy of Sciences and National Natural Science Foundation of China (Grants No.11302236).

\section{References}

Watanabe, N., Aritomi, M., Machida, A.: Time-series Characteristics and geometric structures of drop-size distribution density in dropwise condensation. Int. J. Heat Mass Transfer 76, 467-483 (2014)

Rose, J.W.: Dropwise condensation theory and experiment: a review. Proc. Inst. Mech. Eng 216, 115-127 (2002)

Rose, J.W.: Dropwise condensation theory. Int. J. Heat Mass Transfer 24, 191-194 (1981)

Rose, J.W.: Further aspect of dropwise condensation theory. Int. J. Heat Mass Transfer 19, 1363-1370 (1976)

Rose, J.W.: On the mechanism of dropwise condensation. Int. J. Heat Mass Transfer 10, 755-762 (1967)

Tanasawa: Advances in condensation heat transfer. Adv. Heat Transfer 21, 55-139 (1991)

Collier, J.G. Convective Boiling and Condensation, 2nd. McGrawHill, New York (1981)

Mei, M., Yu, B., Zou, M., Luo, L.: A numerical study on growth mechanism of dropwise condensation. Int. J. Heat Mass Transfer 54, 2004-2013 (2011)

Ma, X.-H.u., Song, T.-Y.i., Lan, Z., Bai, T.: Transient characteristics of initial droplet size distribution and effect of pressure on evolution of transient condensation on low thermal conductivity surface. Int. J. Heat Mass Transfer 49, 1517-1526 (2010)

Ma, X., Rose, J.W., Xua, D., Lin, J., Wang, B.: Advances in dropwise condensation heat transfer: Chinese research. Chem. Eng. J. 78, 87-93 (2000)

Baojin, Q., Li, Z., Hong, X., Yan, S.: Experimental study on condensation heat transfer of steam on vertical titanium plates with different surface energies. Exp. Thermal Fluid Sci. 35, 211-218 (2011)

Son, C.-H., Oh, H.-K.: Condensation heat transfer characteristics of carbon dioxide in a horizontal smooth tube. Exp. Thermal Fluid Sci. 36, 233-241 (2012)

Gebauer, T., Al-Badri, A.R., Gotterbarm, A., El Hajal, J., Leipertz, A., Fröba, A.P.: Condensation heat transfer on single horizontal smooth and finned tubes and tube bundles for R134a and propane. Int. J. Heat Mass Transfer 56, 516-524 (2013)

Park, I., Kim, S.-M., Mudawar, I.: Experimental measurement and modeling of downflow condensation in a circular tube. Int. J. Heat Mass Transfer 57, 567-581 (2013)

Hao, T., Ma, X., Lan, Z., Jiang, R., Fan, X.: Analysis of the transition from laminar annular flow to intermittent flow of steam condensation in noncircular microchannels. Int. J. Heat Mass Transfer, 745-756 (2013)

Kondou, C., Hrnjak, P.: Condensation from superheated vapor flow of R744 and R410A at subcritical pressures in a horizontal smooth tube. Int. J. Heat Mass Transfer 55, 2779-2791 (2012)

Kim, S.-M., Mudawar, I.: Theoretical model for annular flow condensation in rectangular micro-channels. Int. J. Heat Mass Transfer 55, 958-970 (2012) 
Zhao, Z., Li, Y., Wang, L., Liu, Z., Zheng, J.: Flow and heat transfer characteristics of ambient air condensation on a horizontal cryogenic tube Cryogenics 62, 110-117 (2014)

Le, Q.T., Ormiston, S.J., Soliman, H.M.: A closed-form solution for laminar film condensation from quiescent pure vapours on curved vertical walls. Int. J. Heat Mass Transfer 73, 834-838 (2014)

Pati, S., Kaushik, P., Chakraborty, S., Som, S.K.: Film condensation in presence of non-condensable gases: Interplay between variable radius of curvature and interfacial slip. Int. Commun. Heat Mass Transfer 56, 31-36 (2014)
Son, C.-H., Oh, H.-K.: Condensation heat transfer characteristics of $\mathrm{CO} 2$ in a horizontal smooth- and microfin-tube at high saturation temperatures. Appl. Therm. Eng. 36, 51-62 (2012)

Tang, G.H., Hu, H.W., Zhuang, Z.N., Tao, W.Q.: Film condensation heat transfer on a horizontal tube in presence of a noncondensable gas. Appl. Therm. Eng. 36, 414-425 (2012)

Lee, H., Mudawar, I., Hasan, M.M.: Experimental and theoretical investigation of annular flow condensation in microgravity. Int. J. Heat Mass Transfer 61, 293-309 (2013) 